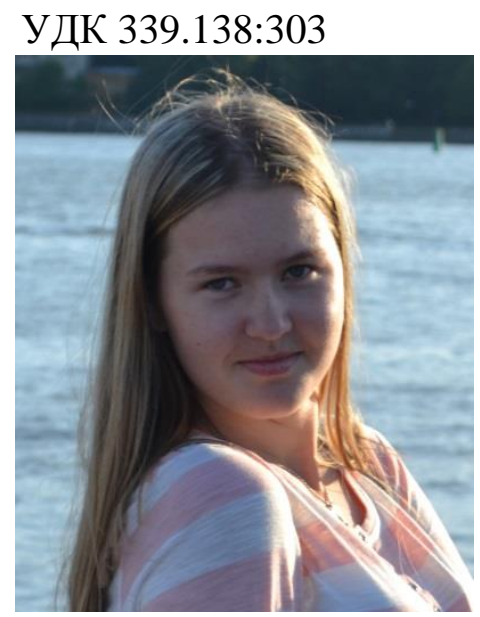

\title{
ВОЗМОЖНОСТИ РЕАЛИЗАЦИИ НЕЙРОМАРКЕТИНГА ДЛЯ АКТИВИЗАЦИИ ПРОДВИЖЕНИЯ ТОВАРОВ ПРЕДПРИЯТИЯ МАЛОГО БИЗНЕСА
}

А. В. Некрасова, студентка 1-го курса магистратуры, e-mail: nastulechkin@mail.ru

ФГБОУ ВО «Калининградский государственный технический университет» психологии. Ключевыми инструментами нейромаркетинга являются ритуалы, на основе изучения которых можно создавать канал взаимодействия с потребителем. Статья посвящена развитию нейромаркетинга и возможностям его применения предприятиями малого бизнеса в целях повышения узнаваемости бренда, увеличения продаж и лояльности потребителей. Представлены достоинства и недостатки внедрения этого направления. Приведены и систематизированы исследовательские методы нейромаркетинга, различные психологические приемы для использования бессознательного в маркетинговых коммуникациях. Представлено несколько практических примеров успешной реализации нейромаркетинга известными компаниями. Статья будет интересна специалистам, интересующимся креативными маркетинговыми коммуникациями на стыке психологии, социологии и экономики.

Ключевые слова: маркетинг, реклама, нейромаркетинг, методы продвижения товара, поведение потребителей, мальй бизнес

\section{ВВЕДЕНИЕ}

Бессознательное потребителя и нейромаркетинг сегодня находятся в самых перспективных исследованиях на стыке экономики и психологии.

Нейромаркетингом называется формальное исследование реакций человеческого мозга на рекламные и маркетинговые сообщения и их корректирование в целях более глубокого и эффективного воздействия [1].

Термин был предложен профессором Университета Эразма Роттердамского Эйлом Смидтс в 2002 г. Как явление, нейромаркетнг появился позже, лишь в XX в., во время бурного развития информационных технологий.

Нейромаркетинг позволяет влиять на подсознание потребителя, это направление сегодня активно формируется и развивается. Самой интересной областью для изучения маркетологи негласно признают бессознательные процессы обработки информации в головах потребителей. Ведь если понять и предсказать желания потребителя раньше конкурентов, это скажется на продажах самым положительным образом.

\section{ОБЪЕКТ ИССЛЕДОВАНИЯ}

Объектом исследования является малый бизнес. В связи с постоянным изменением запросов потребителей он вынужден искать новые способы привлечения клиентов [2]. Такой традиционный метод сбора данных, как опросы не дает столь сильного эффекта, как изучение стратегий поведения целевой аудитории. Потребитель не всегда сам понимает свои желания, а грамотно изложить свои предпочтения и антипатии в таком случае становится почти невозможно. Некоторые же просто не хотят говорить об этом по разным причинам. 
Вышеприведенные факты подчеркивают актуальность выбранной темы. Научная новизна, положенная в основу статьи, состоит в рассмотрении возможности адаптации технологий нейромаркетинга, применяемых предприятиями крупного бизнеса для продвижения малого бизнеса. Методы нейромаркетинга дают широкие возможности для анализа эмоциональных реакций потребителей на бренд, услугу или товар, что значительно улучшает продвижение компании на рынке.

\section{ЦЕЛЬ И ЗАДАЧИ ИССЛЕДОВАНИЯ}

Целью исследования является анализ возможностей реализации нейромаркетинга в продвижении товаров и услуг предприятий малого бизнеса.

Согласно поставленной цели сформулированы следующие задачи:

- проанализировать сущность нейромаркетинга;

- изучить методы нейромаркетинга;

- привести примеры применения нейромаркетинга на практике;

- рассмотреть перспективы нейромаркетинга и его недостатки.

\section{МЕТОДЫ ИССЛЕДОВАНИЯ}

Нейромаркетинг включает в себя множество различных инструментов, которые способствуют облегчению взаимодействия между потребителем и производителем, помогают продавцам осуществлять выгодные продажи. Нижеприведенные исследовательские методы в нейромаркетинге в настоящее время востребованы больше всего:

- ФМРТ (функциональная магнитно-резонансная томография). Визуально отображает активность мозга при контакте с внешним стимулом. На основе данных ФМРТ маркетологи разрабатывают самые действенные рекламные сообщения, вызывающие нужную реакцию;

- ЭЭГ (электроэнцефалография). Измеряет ритмы активности мозговых нейронов, показывающие изменение эмоций и внимания (рис. 1);

- замеры физиологических параметров (частота дыхания, сердечный ритм, электрическое сопротивление кожи) при контакте с раздражителем;

- фиксация сокращений лицевых мимических мышц посредством камеры с высоким разрешением. Необходима для распознавания эмоций в конкретный момент.

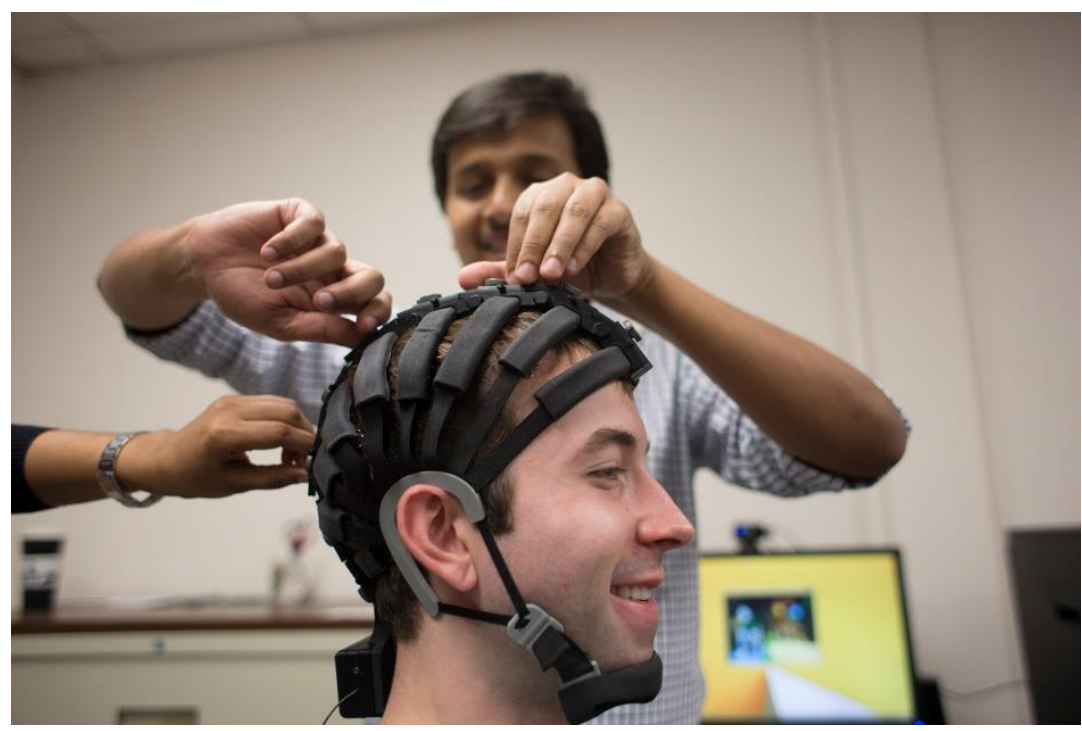

Рисунок 1 - Применение электроэнцефалографии

Еще одним методом нейромаркетинга является айтрекинг (видеотрекинг), благодаря которому можно получить уникальную информацию о том, куда, на что и как 
долго был направлен взгляд зрителя. Эти сведения активно применяют при изучении эффективности рекламных видеороликов, фильмов и текстов [3].

С помощью айтрекинга было установлено, что в фокусе внимания человека всегда оказывается лицо. Оно является самым интересным объектом для наших глаз, и это касается даже условных или схематичных изображений. Кроме того, мы всегда неосознанно отслеживаем направление взгляда собеседника (или лица на картинке): в реальной жизни мы всегда посмотрим туда же, куда и объект нашего внимания (рис. 2).

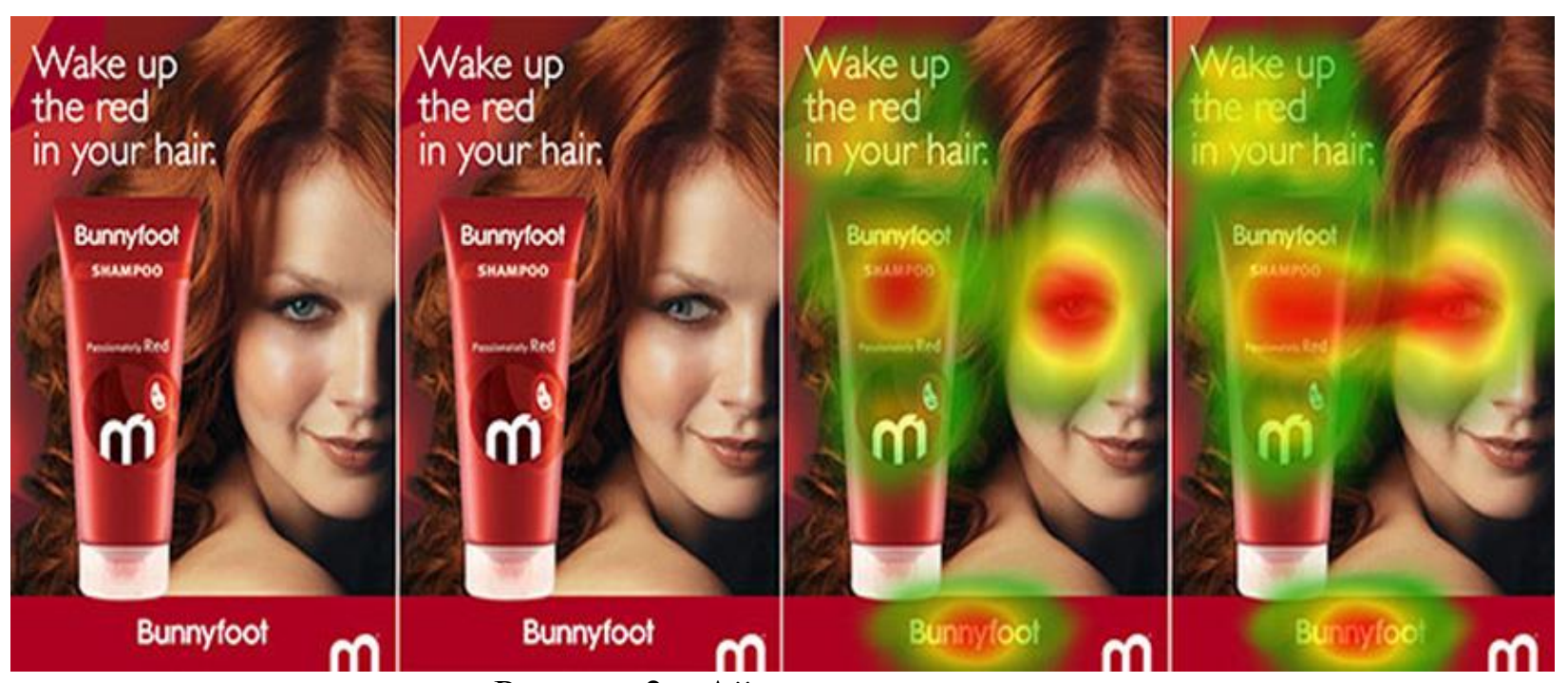

Рисунок 2 - Айтрекинг в рекламе

Реклама CarBakersSkodaFabia: применив айтрекинг, решено было сделать акцент на логотипе Skoda при его прикреплении (а не на названии модели, как обычно), чтобы увеличить узнаваемость бренда [4].

Oticon, известный производитель детских слуховых аппаратов, заказал нейромаркетинговое исследование, когда обнаружил неприязнь потребителей к своим товарам. Обнаружилось, что слуховые аппараты вызывали ассоциацию со старостью и дряхлостью. Чтобы избежать этого, Otikon разработал для своих аппаратов новый модный дизайн.

Всемирно известный автоконцерн Volkswagen тоже не обошёлся без айтрекинга и определённого выстраивания визуального ряда. Бренд стал более узнаваемым и популярным после выпуска видеоролика, в последнем кадре которого присутствовала фраза “Безопасность существует!". На неё и был сделан акцент.

В России направление нейромаркетинга пока развито слабо, и под его маркой понимаются множество различных услуг, кроме самого нейромаркетинга. Например, вам могут предложить помощь в подборе аудиодорожек или ароматов, которые будут способствовать увеличению продаж в магазинах. В большинстве коммерческих предложений, содержащих этот термин, понятия явно (и, видимо, нарочно) подменяются.

\section{РЕЗУЛЬТАТЫ ИССЛЕДОВАНИЯ}

Изначально методы нейромаркетинга не были предназначены для малого бизнеса. Даже сегодня они активно применяются главным образом предприятиями крупного и среднего бизнеса. И, несмотря на свою привлекательность, нейромаркетинг сейчас слабо адаптирован для малого бизнеса. Однако предприниматели постепенно начинают проявлять интерес к данному направлению маркетинга, так как его использование не требует серьезных денежных вложений (если использовать готовые исследования), а также позволяет лучше понять своего потребителя, обойти конкурентов и увеличить продажи [5]. 
Вот некоторые психологические триггеры, которые применяются на практике в нейромаркетинге: покупки.

1. Сейчас или никогда! Ограничение в количестве товара и времени совершения

Каждый человек боится что-то потерять, поэтому вероятность лишиться чего-то служит сильным мотиватором к покупке. На клиента давят не только временные рамки, но и ощущение дефицита, что запускает легкую панику упустить предлагаемый товар навсегда.

2. Делай как я: все пошли - и я пошел.

Человек - существо социальное. И пусть каждый из нас считает себя неповторимым и уникальным, но мнение общества для многих очень важно, поэтому триггер “стадность” всегда действовал и продолжает работать.

Если добавить на сайт (лендинг, рекламный модуль и т. п.) фразы вроде "Нашей услугой воспользовались уже 1657 человек”, то зритель обязательно захочет стать очередным покупателем: ведь если столько людей уже приобрели это, может, и ему надо?

3. VIP-предложение. Я - не такой, как все!

Несмотря на предыдущее утверждение, что мнение общества оказывает на нас большое влияние, есть и другое понятие - понятие эксклюзива, которое действует ничуть не хуже. Специалисты по нейромаркетингу по-разному обыгрывают желание человека выделиться и получить то, чего нет у других. Потребителю предлагают просмотр закрытого контента, эксклюзивные товары из ограниченной серии, статус VIP и многое другое.

4. Ты мне - я тебе.

Вопреки современному циничному взгляду на общество, люди часто отвечают добром на добро. Кроме того, желание отплатить или утолить чувство вины тоже идет с нами рука об руку. Поэтому маркетологи с большим удовольствием играют на этих чувствах.

Отличный пример взаимных добрых дел - призыв ставить лайки, репостить объявление, подписываться на паблик, заполнять анкету или делать ещё что-то подобное, а в обмен дарить подарки или скидки, начислять бонусные баллы, давать возможность скачать книгу и т. п.

5. Жадность вкупе с «халявой».

Однако кроме добрых порывов и мук совести людям не чужды и порывы ко всему бесплатному и получению дополнительной выгоды. Почему бы маркетологу не сыграть на этих слабостях?

Как можно задействовать человеческую жадность в нейромаркетинге? Это всевозможные акции и распродажи, конкурсы с подарками и различные бонусы, например, “3 товара по цене 2-x”, “бесплатный кофе за чек-ин”, “собери 10 наклеек и получи сковороду в подарок".

6. А что будет дальше?

Каждый хоть раз в жизни испытывал чувство заинтригованности и разочарования, когда заканчивалась серия любимого сериала или когда переворачивалась последняя страница первой части книги. Нас всегда дразнят многозначительным “продолжение следует”. И, конечно же, зритель/читатель не захочет пропустить следующую серию/часть, ведь хочется знать, чем все закончится.

Интрига ничуть не хуже работает в продажах. Вот самые очевидные варианты:

Обещание "Читайте в следующем выпуске о..." после статьи.

“Сюрприз для тех, кто досмотрит до конца!” - в начале видеоролика. 


\section{Cmpax.}

Страх - одно из самых сильных наших чувств. И кроме страха потери, есть еще много других. Люди боятся множества разных вещей: высоты или тесного пространства, насекомых, старости или ссоры с близкими.

При формировании образа потенциального потребителя очень важно учитывать его страхи и опасения. Это может, например, помочь сформулировать название статьи, и заголовок вроде "7 принципов здоровых отношений, помогающих создать семью" будет очень триггерным.

\section{8. Сочиальное доказательство.}

Ранее уже было сказано, насколько важно для нас общественное мнение. Поэтому если о товаре положительно расскажут СМИ или им воспользуется звезда, это отлично скажется на имидже как самого товара, так и компании.

Можно задействовать триггер и иным способом: наглядно показать, насколько востребован ваш продукт среди потребителей. Можно поместить на главную страницу самые востребованные позиции товарного каталога с пометкой “Хит продаж!” Это гарантированно привлечёт внимание клиента.

\section{9. Предрассудки и предубеждения.}

Никто не свободен от стереотипов: они формируются на протяжении всей нашей жизни, и на их основе мы принимаем решения. Например, китайские товары мы считаем дешевыми и некачественными, а вот немецкие - дорогими и «долгоиграющими». Считается, что во времена СССР все пищевые продукты были полезнее, потому что были сделаны по ГОСТам.

Нейромаркетинг - активно развивающееся направление. Существуют лаборатории, где ведётся большое количество исследований. В частности, компания Nielsen, занимающаяся измерениями.

Самые нашумевшие исследования за последние 15 лет:

- Эксперимент FritoLay, показавший, что глянцевая рекламная продукция более привлекательна, чем выполненная на матовой бумаге;

- Редизайн супов Campbell's на основе обширного, охватившего 1500 респондентов, исследования;

- Прогнозирование успешности фильмов по трейлерам компании InnerscopeResearch (было задействовано 40 трейлеров).

\section{ЗАКЛЮЧЕНИЕ}

Результаты проведенной в ходе исследования работы содержат как теоретическую, так и практическую значимость. Были изучены теоретические и методологические аспекты нейромаркетинга, выявлена специфика его технологий. Обоснована целесообразность и возможность использования технологии нейромаркетинга для продвижения товаров предприятий малого и среднего бизнеса, определены перспективы и ограничения его использования. Одним из главных ограничений является слабая изученность механизмов работы подсознания, что зачастую не позволяет делать однозначные выводы. Наравне с этим возникают вопросы, связанные с этичностью, ведь корпорации получают возможность добыть ту информацию о клиентах, которую люди не в состоянии скрыть, даже если бы захотели. Однако высокая исследовательская активность свидетельствует о широких перспективах нейромаркетинга, его востребованности и активном развитии.

\section{СПИСОК ЛИТЕРАТУРЫ}

1. Старостина, А. С. Нейромаркетинговые исследования поведения потребителей / А. С. Старостина // Вестник университета (Государственный университет управления). 2015. - № 3. - C. 83-86. 
2. Некрасова, А. В. Особенности формирования системы маркетингового управления для предприятий малого бизнеса / А. В. Некрасова, С. В. Саванович // Современные проблемы отраслевой экономики и управления: мат-лы IX нац. науч.-практ. конф. обучающихся в магистратуре и аспирантуре (15-16 ноября 2019 г.). - Калининград: Изд-во ФГБОУ ВО "КГТУ", 2019. - С. 135-140.

3. Дуглас, В. П. Бессознательный брендинг. Использование в маркетинге новейших достижений нейробиологии / В. П. Дуглас. - Москва: Издательская Группа АзбукаАттикус, 2013. - 380 с.

4. Десять новейших нейромаркетинговых исследований (ключевые выводы) [Электронный pecypc]. URL: https://lpgenerator.ru/blog/2018/10/24/10-novejshihnejromarketingovyh-issledovanij-klyuchevye-vyvody/ (дата обращения 10.02.2020)

5. Шадрин, В. Г. Использование бессознательного в маркетинговых коммуникациях потребителя с брендом / В. Г. Шадрин, О. В. Коновалова, М. А. Шемчук // Креативная экономика. - 2019. - Т. 13. - № 11. -С. 2289-2300.

\title{
OPPORTUNITIES FOR IMPLEMENTING NEUROMARKETING TO IMPROVE THE EFFECTIVENESS OF SMALL BUSINESS PRODUCT PROMOTION
}

\author{
A.V. Nekrasova, 1st year master's student \\ e-mail: nastulechkin@mail.ru \\ Kaliningrad State Technical University
}

The article considers one of the promising directions of innovative marketing neuromarketing, which is located at the intersection of Economics and psychology. The key tools of neuromarketing are rituals, based on the study of which you can create a channel of interaction with the consumer. The article is devoted to the development of neuromarketing and the possibilities of its application by small businesses in order to increase brand awareness, increase sales and consumer loyalty. The advantages and disadvantages of implementing this direction are presented. The paper presents and systematizes research methods of neuromarketing, various psychological techniques for using the unconscious in marketing communications. The article presents several practical examples of successful implementation of neuromarketing by well-known companies. The article will be of interest to specialists who are interested in creative marketing communications at the intersection of psychology, sociology and Economics.

Key words: marketing, advertising, neuromarketing, product promotion methods, consumer behavior, small business 